\title{
A psicologia ensinada a normalistas: um estudo de manuais de ensino
}

\author{
Ana Laura Godinho Lima \\ Universidade de São Paulo - São Paulo - SP - Brasil
}

\section{Resumo}

Este artigo analisa os discursos sobre a psicologia e suas contribuições para a educação a partir do exame de manuais dessa disciplina empregados nas escolas normais durante a primeira metade do século XX. Tais discursos são tomados como acontecimentos e objetos históricos, indícios de que houve, num período não muito distante, outro modo de pensar o valor da psicologia para os professores. Os manuais foram escritos a partir da experiência de seus autores como professores da disciplina e alguns consistem na publicação de suas aulas, ministradas conforme os programas então vigentes. No período considerado, reivindicava-se para a psicologia o status de ciência autônoma, separada da filosofia e situada entre a biologia e a sociologia, com as quais completava o conjunto das ciências que tomavam o homem como objeto de estudo. A disciplina era apresentada como uma ciência nova e promissora, cujo estudo poderia proporcionar bases seguras à educação da criança.

Palavras-chave: Psicologia e educação; livro didático; ensino normal.

\section{Psychology taught to the training college students: a study of textbooks}

\begin{abstract}
This article analyzes the discourses on psychology and its contributions to education from the examination manuals that subject employed in training colleges during the first half of the twentieth century. Such speeches are taken as historical events and objects, evidence that there was, in a not too distant time, another way of thinking about the value of psychology for the teachers. The manuals were written from the experience of the authors as the subject teachers and some consist in the publication of their classes, taught according to the current programs. In the period considered, it claimed, to psychology the status of an autonomous science, separated from philosophy and located between biology and sociology, in which completed all the sciences that took man as an object of study. The subject was presented as a promising new science, whose study could provide a secure basis for the child's education.
\end{abstract}

Keywords: Psychology and education; textbook; normal education.

\section{La psicología enseñada a normalistas: un estudio de manuales de enseñanza}

\section{Resumen}

Este artículo analiza los discursos sobre la psicología y sus contribuciones a la educación a partir del examen de manuales de esa asignatura empleados en las escuelas normales durante la primera mitad del siclo XX. Esos discursos son tomados como acontecimientos y objetos históricos, indicios de que hubo, en un período no muy lejano, otro modo de pensar el valor de la psicología para los profesores. Los manuales fueron escritos a partir de la experiencia de sus autores como profesores de la asignatura y algunos consisten en la publicación de sus clases, impartidas de acuerdo con los programas en vigentes. En el período considerado, se reivindicaba para la psicología el status de ciencia autónoma, separada de la filosofía y ubicada entre la biología y la sociología, con las cuales completaba el conjunto de las ciencias que tomaban el hombre como objeto de estudio. La asignatura era presentada como una ciencia nueva y promisora, cuyo estudio podría proporcionar bases seguras a la educación del niño.

Palabras clave: Psicología y educación; libro didáctico; enseñanza normal. 


\section{Introdução}

A psicologia, em suas interfaces com a pedagogia, tem sido alvo de uma série de questionamentos. O já clássico estudo A produção do fracasso escolar transformou os modos de pensar as relações entre essas disciplinas e desencadeou grande parte das críticas à psicologia escolar no Brasil. A pesquisa empreendida por Maria Helena Souza Patto mostrou como a psicologia participou na naturalização dos chamados problemas de aprendizagem, ao atribuir as dificuldades enfrentadas pelos alunos nas escolas a deficiências individuais ou à inadequação familiar. A autora evidenciou ainda o modo como a psicologia, ao dedicar-se a produzir conhecimentos objetivos sobre os alunos e suas capacidades por meio da elaboração de testes para a mensuração da inteligência e de outros tipos de avaliação, passou a atribuir status de verdade à desqualificação dos alunos que não se saíam bem na escola em tais procedimentos diagnósticos. Esses alunos, majoritariamente pertencentes a camadas mais desfavorecidas da população, eram avaliados por especialistas que ocupavam posições sociais privilegiadas e que apresentavam uma série de preconceitos em relação às crianças pobres e aos modos de vida de suas famílias. Suas concepções se refletiam na produção de testes e inquéritos por meio dos quais os maus alunos eram avaliados e, quase sempre, julgados como incapazes ou imorais. A partir do recurso à psicologia, o fracasso escolar foi sistematicamente explicado como consequência da incapacidade biológica da criança ou da incompetência de sua família, desconsiderando-se a possibilidade de participação da própria escola na produção de entraves no aprendizado (Patto, 1990; Carvalho, 2011).

A leitura da obra de Maria Helena Patto e de outras investigações realizadas na mesma perspectiva convoca aqueles dedicados à formação docente a se perguntarem: Ainda faz sentido ensinar psicologia a professores em formação? É possível vislumbrar uma psicologia da educação que não pretenda simplesmente desqualificar os comportamentos não-conformes da criança na escola e promover o ajustamento do aluno às expectativas dos professores e de seu grupo social?

A partir do exame de manuais de psicologia empregados nas escolas normais da primeira metade do século $\mathrm{XX}$, este artigo analisa os discursos sobre a disciplina e sua importância na formação docente. Considera-se que conhecer o que os antigos professores - sobre os quais ainda não pesavam esses questionamentos - puderam dizer aos alunos acerca do que é a psicologia e do tipo de contribuição que ela tem a oferecer para a educação pode ampliar a compreensão a respeito do tema. O que era possível dizer e já não o é mais? O que ainda continuamos a dizer? Talvez esse reconhecimento possa ajudar a vislumbrar alternativas ainda não formuladas para a psicologia em sua aproximação com a educação no período em que ela se tornou suspeita de ser a causa de algumas das dificuldades enfrentadas pelos alunos e seus professores na escola.
Os manuais de psicologia publicados nas primeiras décadas do século $X X$ foram elaborados com o propósito de apresentar, resumida e didaticamente, os conhecimentos então disponíveis sobre a psicologia, frutos principalmente de pesquisas conduzidas na Europa e nos Estados Unidos. Os dez manuais aqui considerados foram escritos a partir da experiência de seus autores como professores dessa disciplina nas escolas normais e alguns deles consistem na publicação de suas aulas, ministradas conforme os programas vigentes à época. $A$ análise de tais livros didáticos permite uma aproximação dos modos como os professores conduziam o ensino da matéria para os normalistas. Algumas indagações podem ser formuladas a propósito desses compêndios: Como a psicologia era apresentada aos alunos das escolas normais? Como se explicava aos futuros professores a importância desta disciplina para sua formação? Como se organizavam os saberes da psicologia em uma sequência de aulas ou lições? Que aproximações e distanciamentos, repetições e distinções se podem observar nos enunciados sobre a psicologia veiculados em manuais distintos, mas redigidos com propósito semelhante?

Já há décadas, pesquisadores brasileiros das áreas da psicologia, da história e da pedagogia vêm buscando elucidar diferentes aspectos das relações que se estabeleceram entre a psicologia e a educação desde o século XIX. Tais investimentos geraram uma extensa produção bibliográfica, de modo que uma apresentação adequada do conjunto dessas investigações ultrapassa as possibilidades deste texto. Parte dos trabalhos debruçou-se sobre os manuais de psicologia empregados na formação docente, tomando-os como fonte para a investigação de questões relativas aos seus conteúdos (Cysneiros, 1985; Ferreira, 1986; Angelini, Pfromm Neto, \& Rosamilha, 2001; Assunção, 2007; Silva, 2008) e ao modo como os livros tratavam de diferentes temas - a afetividade (Assunção, 2008), a criança normal (Silva \& Gallego, 2011) - ou teorias - o behaviorismo (Gioia, 2001), as teorias sobre o desenvolvimento infantil (Gouvêa \& Bahiense, 2011; Eddine, 2011), a teoria histórico-cultural de Vigotski (Jácome, 2006).

Nesta análise, pretende-se examinar os manuais não como documentos que se referem a outros objetos ${ }^{1}$ (a psicologia, suas teorias, seus conceitos, suas verdades, seus usos legítimos e ilegítimos, ou os autores, suas concepções, suas preocupações, seus interesses), mas como monumentos, como coisas raras dotadas de uma história e de características próprias. Assim, importa compreendê-los em suas relações com uma série de acontecimentos e outros objetos - instituições, teses, teorias -, dos quais seus discursos não são espelhos fiéis nem cópias distorcidas. Os manuais tampouco são aqui tomados como descrição simplificada de conteúdos cujo sentido genuíno estaria por trás dos enunciados manifestos ou cuja integridade seria preciso restituir a partir do retorno às fontes originais. São, antes, entendidos como coisas ao lado de outras coisas, de outros discursos. Tendo em vista as considerações de Foucault

1 bbjeto do discurso, compreendido como aquilo de que se fala, a que o discurso se refere (Foucault, 2004, p. 45 e seguintes). 
(2004) em A arqueologia do saber, esta análise renuncia a considerar os enunciados contidos nos manuais como "tradução' de operações ou de processos que se desenrolam em algum outro lugar (no pensamento dos homens, em sua consciência ou em seu inconsciente, na esfera das constituições transcendentais)" (p. 138). Propõe, alternativamente, que o enunciado

seja aceito, em sua modéstia empírica, como local de acontecimentos, de regularidades, de relacionamentos, de modificações determinadas, de transformações sistemáticas; em suma, que seja tratado não como resultado ou vestígio de outra coisa, mas como um domínio prático que é autônomo (apesar de dependente) e que se pode descrever em seu próprio nível (se bem que seja preciso articulá-lo com algo que não seja ele). (Foucault, 2004, p. 138).

Pretende-se verificar, na análise conjunta dos manuais selecionados, se é possível identificar um discurso comum sobre a psicologia destinado aos professores, entendendo-se discurso como "um conjunto de enunciados que se apoia em um mesmo sistema de formação" (Foucault, 2004, p. 122). É preciso observar, contudo, que a definição de enunciado formulada por Foucault supõe um modo de delimitação próprio, pois, conforme o autor, embora o enunciado possa ser expresso na forma de uma frase, afirmação ou sentença, ele não equivale a essas unidades textuais.

Descrever um enunciado não significa isolar e caracterizar um segmento horizontal, mas definir as condições nas quais se realizou a função que deu a uma série de signos (não sendo esta forçosamente gramatical nem logicamente estruturada) uma existência, e uma existência específica. Esta a faz aparecer não como um simples traço, mas como relação com um domínio de objetos; não como resultado de uma ação ou de uma operação individual, mas como um jogo de posições possíveis para um sujeito; não como uma totalidade orgânica, autônoma, fechada em si e suscetível de - sozinha - formar sentido, mas como um elemento em um campo de coexistência; não como um acontecimento passageiro ou um objeto inerte, mas como uma materialidade repetível. (Foucault, 2004, p. 123).

Os enunciados são materialidades repetíveis, o que não quer dizer que se deva procurar por suas reproduções literais em fontes diversas, pois um mesmo segmento de texto em superfícies distintas pode produzir diferentes enunciados, dependendo dos outros enunciados a que se encontra associado em cada caso. Por outro lado, uma paráfrase, um exemplo, uma legenda ou um gráfico podem consistir em múltiplas aparições de um mesmo enunciado, ao exercerem a mesma função em dado discurso. Não cabe, pois, efetuar registros automáticos de segmentos textuais idênticos, mas procurar perceber se as formulações sobre a psicologia nos diferentes manuais obedecem a um mesmo regime de formação.
As considerações a seguir tecem-se como uma possibilidade de análise dos enunciados contidos nos manuais de psicologia, buscando tomá-los como acontecimentos e como objetos históricos, como indícios de que houve, numa época não muito distante de nós, outro modo de pensar o valor da psicologia para os professores, um modo de pensar do qual talvez estejamos apenas começando a nos distanciar.

\section{Escola seriada, psicologia e formação de professores}

Ao longo do século $X X$, a psicologia ocupou a posição de uma disciplina central nos currículos de formação de professores. Acreditou-se que as descobertas sobre a psicologia do aluno estabeleceriam bases seguras para as práticas pedagógicas. Essa expectativa já se manifestava nos discursos da pedagogia e da psicologia desde a última década do século XIX, quando se envidaram esforços na criação de um sistema público de ensino baseado nos grupos escolares e nas escolas normais para a formação dos professores. As novas escolas seriadas instituíram a homogeneização das classes por meio da divisão dos alunos em turmas da mesma idade e com aproximadamente o mesmo nível de conhecimentos. Nessas condições, as diferenças de aproveitamento entre as crianças logo se evidenciaram, apresentando-se como um problema em uma escola organizada para realizar o ensino simultâneo. Os alunos que não conseguiam aprender no ritmo esperado representavam um entrave para a administração do ensino, pois ao mostrarem-se refratários à instrução e à moralização escolar, eram temidos como uma ameaça à sociedade, propensos a se transformarem em delinquentes ou adultos desajustados e improdutivos (Rose, 2008; Donzelot, 2001).

O ensino sistemático da psicologia nas escolas normais ocorreu a partir das primeiras décadas do século XX. Inicialmente, isso se deu por meio do desdobramento da disciplina Pedagogia em Pedagogia e Psicologia, tal como ocorreu em São Paulo, a partir de 1912, e no Rio de Janeiro. Segundo Lourenço Filho (1954), a introdução da psicologia no currículo de formação dos professores não se fez de forma definitiva, pois, no Distrito Federal, a disciplina foi facultativa por vários anos. Em 1928, a psicologia foi oficialmente inserida no currículo das escolas normais por meio de um decreto, simultaneamente à incorporação da pedagogia, da história da educação, da didática, da sociologia, da higiene e da puericultura (Antunes, 2007).

$\mathrm{Na}$ década de 1920 realizaram-se reformas educacionais em vários estados brasileiros. Na Bahia, a reforma foi conduzida por Anísio Teixeira; no Distrito Federal, por Fernando de Azevedo; em Minas Gerais, por Francisco Campos. Lourenço Filho esteve à frente das reformas empreendidas no Ceará e em São Paulo. Gradativamente, os problemas da educação, que até então haviam sido enfrentados por políticos e intelectuais de diversas áreas, tornaram-se objeto de profissionais dedicados ao ensino escolar. Observou-se um aumento do número de publica- 
ções sobre educação, em que passaram a ser divulgados os princípios da Escola Nova (Nagle, 1976). O movimento da Escola Nova começou na Europa nos anos iniciais do século $X X$, no âmbito de instituições de correção e tratamento para crianças que se mostravam impermeáveis à educação escolar. Seus representantes transformaram o aluno no centro da ação pedagógica e criticaram as práticas escolares tradicionais, em especial o controle rígido dos horários e dos usos do espaço, bem como os procedimentos de exame. Propuseram-se a substituir o sistema de transmissão de conhecimentos do mestre ao aluno pela composição de um espaço educativo a ser livremente explorado pela criança durante períodos de tempo flexíveis. A educação passava a ser compreendida como recurso profilático e terapêutico para os casos de desajustamento social.

A Escola Nova aparecia, então, como inovadora, libertária e científica, com práticas fundamentadas em conhecimentos objetivos sobre a psicologia da criança (Varela, 1999). No Brasil, o movimento foi levado adiante por educadores e intelectuais prestigiados, como Sampaio Dória, Lourenço Filho e Noemi da Silveira Rudolfer, que foram professores de psicologia na Escola Normal de São Paulo e signatários do Manifesto dos Pioneiros da Educação Nova. O documento, de 1932, além de defender a escola ativa organizada segundo prescrições científicas, reivindicava a escola pública, laica, gratuita e obrigatória, bem como a coeducação dos sexos (Vidal, 2013).

Os manuais de psicologia para o ensino normal aqui considerados foram publicados entre 1900 e 1949. Num tempo em que ainda não havia curso superior de psicologia no Brasil, os docentes que ministravam a matéria nas escolas normais eram oriundos de outros campos de formação - frequentemente, a medicina e o direito. Essas duas áreas do conhecimento dedicavam-se, então, a formular alternativas cientificamente fundamentadas para a superação dos problemas sociais. A constituição biológica do povo brasileiro era motivo de preocupação por parte de médicos e juristas, que viam negros e índios como tipos inferiores e temiam o processo de miscigenação, pois, conforme teorias importadas da Europa, a mistura das raças produzia indivíduos degenerados que tendiam a herdar as piores características das raças originais (Schwarcz, 1993; Patto, 1999). Os modos de intervenção da medicina e do direito eram pensados principalmente na perspectiva da prevenção, como ilustra o seguinte excerto de um artigo publicado em 1908 na Revista da Faculdade de Direito de São Paulo: "A Medicina cumpre prevenir as moléstias antes que cural-as. Ao Direito cumpre prevenir e resolver os delitos antes que punil-os" (citado por Schwarcz, 1993, p. 179).

As primeiras pesquisas conduzidas entre nós sobre questões psicológicas foram realizadas nas faculdades de medicina no Rio de Janeiro e na Bahia, a partir de meados do século XIX. Enquanto no Rio de Janeiro os trabalhos incidiam principalmente sobre questões relacionadas à neuropsiquiatria e à neurologia, na Bahia privilegiavam-se temas associados à criminologia, à higiene mental e à psicologia social e pedagógica (Lourenço Filho, 1954).
Dentre os autores dos manuais de psicologia examinados, três eram médicos formados no Rio de Janeiro. Dois deles, Manoel Bomfim e Plínio Olinto, estudaram na mesma faculdade e lecionaram na Escola Normal do Rio de Janeiro.Em 1902, Bomfim foi a Paris para estudar psicologia. Lá foi discípulo de Alfred Binet, com quem planejou a criação do primeiro laboratório de psicologia do país, no Pedagogium. Além de participar em seu planejamento e em sua instalação, ocorrida em 1906, Bomfim dirigiu-o por 15 anos. Redigiu os manuais Lições de pedagogia (1915) e Noções de psychologia, cuja primeira edição data de 1916, ambos frutos de seu trabalho como professor (Antunes, 2001a). Plínio Olinto, autor de Psicologia (1934), trabalhou por dois anos no Laboratório de Psicologia do Hospital Nacional de Psicopatas do Rio de Janeiro, antes de ingressar, em 1916, na Escola Normal, onde passou a trabalhar com Manoel Bomfim, lecionando psicologia até 1930 (Penna, 2001).

lago Pimentel, também formado no Rio de Janeiro, passou a atuar,em 1922, como psiquiatra no Instituto Neuro-Psiquiátrico de Belo Horizonte, onde ajudou a implementar procedimentos psicológicos (como os testes mentais) na realização de diagnósticos. Por ocasião da reforma do ensino primário, levada a efeito por Francisco Campos em Minas Gerais, tornou-se professor de psicologia educacional na Escola Normal Modelo de Belo Horizonte. Escreveu, a partir dessa experiência, Noções de psicologia aplicadas à educação (1947) e Notas de psicologia (1959). O autor aproximou-se do trabalho de Helena Antipoff, psicóloga russa que havia sido discípula de Claparède no Laboratório de Psicologia da Universidade de Genebra e depois veio ao Brasil, tendo se estabelecido em Minas Gerais e se dedicado à educação de crianças deficientes mentais. A especialista esteve à frente da criação da Sociedade Pestalozzi, em 1932. Pimentel trabalhou no atendimento às crianças excepcionais no consultório médico-pedagógico desta instituição desde seu início (Lourenço \& Tinoco, 2001).

Valentim Magalhães, Sampaio Dória e Djacir Menezes, autores de outros três manuais, formaram-se advogados. Magalhães, nascido em 1859 no Rio de Janeiro, fez o curso de direito, mas atuou como jornalista, contista, romancista e poeta, além de ter sido um dos fundadores da Academia Brasileira de Letras. Foi professor de português e pedagogia na Escola Normal do Rio de Janeiro e, como resultado dessa experiência, publicou, em 1900, Lições de pedagogia, cuja primeira parte é dedicada à psicologia. Sampaio Dória atuou principalmente como educador e político. Tornou-se professor de psicologia na Escola Normal de São Paulo em 1914, quando nela foi instalado o primeiro Gabinete de Antropologia Pedagógica e Psicologia Experimental do estado (Tavares, 1995; Carvalho, 1997; Monarcha, 1999). O livro Psychologia (1926) é fruto do trabalho realizado por Sampaio Dória como professor de psicologia na Escola Normal de São Paulo, função em que permaneceu até 1925, quando foi sucedido por Lourenço Filho (Antunes, 2001b).

Djacir Menezes, também advogado, tornou-se doutor em ciências jurídicas e sociais e membro do Instituto Histórico e Geográfico do Ceará, estado onde nasceu em 1907. É 
autor de Psicologia (1933), matéria que lecionou na Escola Normal Pedro II, em Fortaleza, onde também se criou um laboratório para os estudos desta disciplina. De acordo com Mitsuko Antunes (2007), foi a partir desta escola normal que se empreendeu a reforma do ensino do Ceará conduzida por Lourenço Filho em 1922 e 1923, a qual pode ser considerada o primeiro esforço mais expressivo de reformar a educação a partir dos princípios da Escola Nova no Brasil.

Foram encontradas poucas informações sobre os outros autores. Todos eles dedicaram-se à formação docente. Azevedo foi professor na Escola Normal de Santa Rita. Justino Mendes era o pseudônimo de Monsenhor José João Perna, responsável pela cadeira de psicologia da Faculdade de Filosofia Ciências e Letras Santo Tomaz de Aquino em Uberaba. Nada consta no manual de José de Almeida sobre sua formação ou atuação profissional, a não ser uma listagem de seus trabalhos anteriores, todos eles de natureza pedagógica e versando sobre o ensino de diversas disciplinas. Um texto de sua autoria, intitulado Breves consideraciones sobre La Escuela Nova, foi publicado em um periódico estrangeiro, a Revista de Educación. Penteado Junior foi catedrático de didática geral e especial na Faculdade de Filosofia, Ciências e Letras da USP, disciplina sobre a qual também produziu um manual de ensino.

Os dez compêndios examinados apresentam diferenças expressivas quanto ao número de páginas e de capítulos. O menor livro, e também o mais antigo, é Lições de pedagogia (1900), de Valentim Magalhães,comdez capítulos distribuídos em 51 páginas. Os outros manuais apresentam número de páginas que varia entre 157 e 391 distribuídas entre 13 e 30 capítulos. Apesar dessas diferenças e das distintas trajetórias profissionais dos autores, a ordem de exposição da matéria é semelhante em todos eles, o que sugere que a escrita de um novo livro era feita a partir da leitura dos compêndios já disponíveis, inclusive em língua estrangeira.
No prefácio escrito por Manoel Bomfim para o livro Noções de psychologia (1917) tal hipótese é respaldada: "A ordem adotada nesta exposição é a geralmente aceita nas obras congêneres da didática franceza: condições gerais da vida psíquica, sensações, conhecimento, afetividade, vontade" (p. 7). Os manuais citavam principalmente teorias e autores estrangeiros, mas a leitura dos dez livros em conjunto permite notar que eles também se referiam uns aos outros. Nos prefácios, é recorrente a observação de que o livro foi escrito com o singelo objetivo de contribuir para a formação dos alunos das escolas normais e, portanto, não pretendia apresentar uma teoria original, mas apenas expor de maneira didática os conhecimentos já disponíveis sobre a disciplina no Brasil e no exterior. José de Almeida (1947) fornece um exemplo típico: "Livro para estudantes, não apresenta nada de novo em suas páginas, cujas ideias foram buscadas nas obras dos grandes mestres alienígenas e nacionais, que integram a nota bibliográfica deste modesto compêndio" ( $p$. 12).

O capítulo inicial dos manuais costumava ser dedicado a uma introdução em que se apresentava a matéria do curso. Os seguintes eram voltados aos diferentes aspectos da psicologia do indivíduo: sensações, estados afetivos (sentimentos), estados representativos (inteligência) e vontade. A exposição de cada um desses elementos era mais ou menos desenvolvida e apresentava uma quantidade variável de subdivisões, dependendo do grau de detalhamento conferido pelo autor a cada tópico. Em alguns manuais, o estudo da linguagem e das crianças anormais, por exemplo, era tratado em capítulos próprios. O capítulo final costumava ser dedicado ao estudo do caráter e da personalidade, apresentados como síntese das dimensões psicológicas do indivíduo. A análise incidiu sobre os seguintes manuais, apresentados na Tabela 1:

Tabela 1. Manuais analisados.

\begin{tabular}{lll}
\hline Título & Autor & Ano \\
\hline Lições de pedagogia. Parte 1: Psychologia & Magalhães, V. & 1900 \\
\hline Noções de psychologia (2 $\left.{ }^{\text {ed. }}\right)$ & Bomfim, M. & 1917 \\
\hline Psychologia & Sampaio Dória, A. & 1926 \\
\hline Psicologia & Menezes, D. & 1933 \\
\hline Psicologia & Olinto, P. & 1934 \\
\hline Psicologia educacional & Azevedo, N. & 1936 \\
\hline Psicologia educacional: conforme o programa das Escolas Normais de & Mendes, J. & 1943 \\
$1^{\circ}$ e 2 graus & & 1947 \\
\hline Noções de psicologia aplicada à educação & Almeida, J. & 1949 \\
\hline Compêndio de psicologia (problemas de psicologia educacional) (2ª ed.) & Penteado Junior, O.A. \\
\hline Noções de psicologia aplicadas à educação & Pimentel, I. (s.d.). & s.d. \\
\hline
\end{tabular}




\section{A psicologia nos enunciados dos manuais para normalistas}

A leitura dos capítulos introdutórios aos manuais permitiu identificar enunciados recorrentes, os quais dizem respeito ao histórico da psicologia, à sua posição no quadro geral das ciências, à sua definição e delimitação e à sua relevância para a educação. As considerações a seguir buscam descrever um conjunto desses enunciados. Não se pretendeu efetuar um levantamento exaustivo de todos os enunciados que reaparecem em manuais distintos, mas evidenciar a presença de alguns que são particularmente significativos para a compreensão dos aspectos mencionados.

No artigo Psicologia como uma ciência social, Nikolas Rose (2008) observou: "Todo aluno de psicologia conhece a expressão 'a psicologia tem um longo passado, porém uma história curta', como Edwin Boring assinalou de forma bem sucinta" (p.156). Variações desse enunciado, atualmente frequente em livros didáticos de psicologia, já constavam em cinco manuais publicados no Brasil na primeira metade do século XX. Afirmava-se que as questões sobre as quais incide a psicologia eram muito antigas, talvez tanto quanto a própria humanidade, e diziam respeito às especulações sobre a alma e sua relação com o corpo, bem como às tentativas de compreender, prever e controlar o comportamento. Por outro lado, a psicologia como ciência era nova e apenas recentemente havia sido separada da filosofia. Valentim Magalhães (1900) dizia:

A psicologia entrou em uma fase nova, tendo abandonado os domínios nebulosos do racionalismo indefinido, para tomar por base a observação direta dos fenômenos psicológicos, o conjunto dos fatos anteriores quando se procura estabelecer o seu determinismo por meio da experimentação (p. 11).

Na década de 1930, Pimentel (s.d.) sustentava: "tal como é hoje compreendida, isso é, como ciência distinta, separada da filosofia, com a qual, até então, aparecia inteiramente confundida, a psicologia é relativamente muito nova" (p.7). Afirmava-se que os antecedentes mais remotos da psicologia eram a magia, o misticismo e a superstição. Nelson Cunha de Azevedo (1936) indagava: "Assim como a alquimia precedeu a química, a astrologia à astronomia, não teria a Psicologia sido precedida pela quiromancia ou ciências afins?". Em seguida, respondia: "Parece-nos que sim" (p. 13).

Quanto à posição da psicologia entre as demais ciências, quatro manuais traziam o enunciado segundo 0 qual a psicologia situava-se entre a biologia e a sociologia. Plínio Olinto (1934) afirmava: "Os estudos psicológicos tanto dependem da biologia como da sociologia e permanecem como uma ponte de passagem ligando as duas" (p. 11).

Os professores-autores lago Pimentel, Nelson Cunha de Azevedo, Justino Mendes e José de Almeida ensinavam aos normalistas a definição de psicologia recorrendo à etimologia da palavra: "De acordo com a etimologia do vocábulo, psicologia quer dizer ciência da alma" (Pimentel, s.d., p. 8). No livro-texto de Magalhães (1900), o mais antigo entre os examinados, a definição aparecia ampliada: "A psicologia é a ciência que estuda os fatos do espírito, a ciência da alma ou dos fatos anímicos" (p. 7). Esta definição tradicional costumava ser seguida por enunciados que estabeleciam a delimitação do objeto de estudo da psicologia como ciência positiva, desinteressada de questões metafísicas. Nas palavras de Onofre de Arruda Penteado Junior (1949): "A psicologia positiva, puramente científica, não se preocupa com a essência da alma. Interessa-se, tão somente, pelos fenômenos e pelo modo de se manifestarem. Estuda as atividades mentais, sem indagar de sua natureza intrínseca. Não faz metafísica" (p. 10). Antes dele, Sampaio Dória (1926), lago Pimentel (s.d.) e José de Almeida (1947) enunciavam a mesma delimitação, sempre se valendo de analogia semelhante entre a psicologia e a física. Nas palavras de Pimentel (s.d.):

Como ciência positiva, a psicologia é mais modesta e contentase tão somente com o estudo de fenômenos, isto é, de coisas passíveis de serem por nós percebidas. Do mesmo modo que o físico, sem se preocupar com a natureza íntima da luz ou da eletricidade, procura apreciá-las em seus resultados, o psicólogo estuda os fatos que o interessam perscrutando as condições em que se produzem, as causas que os alteram, os efeitos que provocam, tentando apenas traçar-Ihes as leis, isto é, as relações recíprocas e constantes (p. 8).

A definição de psicologia transmitida aos estudantes da Escola Normal da Praça por Sampaio Dória (1926) era expressa da seguinte forma: "A psicologia é um sistema de verdades sobre os estados de consciência" (p.5). Nos manuais de lago Pimentel (s.d.), Justino Mendes (1943) e Onofre de Arruda Penteado Junior (1949),tal enunciado reaparecia.O professor José de Almeida (1947), por sua vez, indicava, em fins da década de 1940, que ainda não havia um consenso sobre a questão ao apresentarem em seu texto a existência de uma controvérsia quanto à definição da psicologia. Entre as diversas definições por ele relacionadas, duas eram recorrentes. A primeira, conforme já se mencionou, determinava que a psicologia consistia na "ciência que estuda as leis dos fatos da consciência" (p.8). A segunda estabelecia que o objeto de estudo da psicologia era o conjunto das formas de adaptação ou ajustamento do indivíduo ao meio. Noções de psychologia registrava que a psicologia consistia na ciência da personalidade, definida como "síntese das atividades psíquicas", as quais, por sua vez, tinham como objetivo "a adaptação ou a acomodação das exigências internas às condições externas" (Bomfim, 1917, p. 14).Em Psicologia, lê-se que a disciplina:

Não é ciência da alma, nem da consciência, nem da matéria. Segundo alguns, nem mesmo ciência ainda não é.

A psicologia estuda as condutas que se definem no comportamento, interpreta as adaptações do indivíduo ao meio, as modificações do meio face ao indivíduo, num ajustamento que é a socialização (Olinto, 1934, p. 11). 
De acordo com esse manual, a tarefa do educador era "tornar mais suave esse ajustamento entre o indivíduo e o meio" (p. 15). A psicologia surgia assim, diante dos leitores-normalistas, como a ciência que, por explicar como ocorria a adaptação do indivíduo ao meio, estava em melhores condições de indicar-lhes como facilitá-la.

Ao justificar a relevância da psicologia para as realizações humanas, os textos referiam-se às suas modalidades como ciências aplicadas, entre as quais sobressaía a psicologia educacional. Parte do capítulo introdutório de Psicologia educacional (1943) era dedicada ao tema "a psicologia experimental e seu aproveitamento na orientação das atividades humanas". Relatava-se o desenvolvimento da aplicação dos conhecimentos psicológicos em diversas áreas, tais como a classificação dos operários na indústria, o estudo dos alienados nos hospícios e a seleção dos alunos nas escolas. Ofereciam-se exemplos de trabalhos desse tipo realizados nos Estados Unidos, na Alemanha, na Itália, na Rússia, na Suíça e na Inglaterra. Em Noções de psicologia aplicadas à educação, enunciava-se: "Dentre as aplicações da psicologia, as mais importantes, porém, são as que dizem respeito às questões relativas à educação da infância e aparecem compendiadas sob o nome de psicologia educacional" (Pimentel, s.d., p. 11). O estudo da psicologia era apresentado como condição indispensável para a renovação do ensino, que deveria se orientar pelo estudo científico da natureza infantil. Em Psicologia, esse enunciado aparecia na forma de uma interrogação: "Quem poderá ensinar crianças sem lhes conhecer a mentalidade?" (Olinto, 1934, p. 15). Perguntava-se, ainda: "Quantos erros cometeu a pedagogia por falta de psicologia?". A segunda questão retornava como uma das três epígrafes de Noções de psicologia aplicada à educação. As outras duas citações iniciais do livro retomavam enunciados de autores estrangeiros: "A psicologia deve constituir a base de toda teoria e de toda a prática da educação. Sem esta indispensável orientação, nossa pedagogia não seria mais que um cego empirismo (M. Devaud)"; "Estudai a criança porque certamente não a conheceis (Rousseau)" (Almeida, 1947). A recomendação de Rousseau, filósofo inspirador do movimento da Escola Nova, já aparecera antes, no compêndio de Nelson Cunha de Azevedo (1936), que, por sua vez, citava-a a partir de um livro de Claparède:

De todas as aplicações que tem a psicologia, sem dúvida alguma, das mais importantes são aquelas que visam a Educação. Claparède, em sua 'Psychologie de l'Enfant', depois de citar a frase de Jean Jacques Rousseau: 'começai por estudar melhor a vossos alunos; porque, com toda certeza, não os conheceis' - diz que a Pedagogia deve repousar sobre o estudo da criança, como a floricultura sobre o conhecimento das flores (p. 20).

Nos discursos dos manuais, a psicologia, em especial a psicologia infantil, era apresentada como o fundamento científico da prática pedagógica. Afirmava-se que a educação da criança só poderia ser bem-sucedida se respeitasse sua natureza. "Só se governa a natureza obedecendo-a" e "Não se governa a natureza senão obedecendo-lhe"eram duas versões do mesmo enunciado, a primeira presente na obra de Nelson Azevedo (1936) e a segunda no compêndio de Justino Mendes (1943). No livro de lago Pimentel (s.d.), tal enunciado aparecia expandido nos seguintes termos:

Estudando os diversos fatores da personalidade, acompanhando-a, principalmente através da evolução física e mental do indivíduo, nos primeiros anos de sua vida, especulando as causas capazes de alterá-la, a psicologia representa, neste caso, o mais sólido apoio da pedagogia hodierna, pois oferece a esta última o ensejo de proporse dirigir a formação da personalidade infantil, segundo princípios baseados no rigor de leis científicas (p. 11).

Para concluir esta breve caracterização dos discursos destinados aos normalistas nas primeiras décadas do século $X X$, vale mencionar um enunciado relativo à competência da psicologia aplicada à educação. Nos manuais de lago Pimentel e Nelson Azevedo, estabelecia-se: "À psicologia não cabe propor os fins últimos da educação junto à educação ela não determina os fins da escola, mas os meios para atingir tais fins" (Azevedo, 1936, p. 20). O livro de Justino Mendes (1943) enunciava, por sua vez, que cabia à psicologia participar na definição dos fins da educação, definindo os limites do que se poderia alcançar, tendo em vista as leis do desenvolvimento da criança.

\section{Considerações finais}

Que interesse pode haver na descrição desses enunciados antigos? Os discursos destinados à formação de professores na primeira metade do século $X X$ evidenciam que a psicologia era apresentada como uma ciência nova e promissora, cujo estudo forneceria bases seguras à organização das práticas educativas. Defendia-se para a psicologia o status de ciência autônoma, separada da filosofia e situada entre a biologia e a sociologia, com as quais completava o conjunto das ciências que tomavam o homem como objeto de estudo em sua tripla condição: um ser que vive, pensa e se move num mundo com o qual se relaciona. A psicologia definia as leis do psiquismo e investigava os modos de adaptação do indivíduo ao meio. Sua contribuição para a educação estava em descrever a natureza infantil para orientar os professores sobre como governar a criança na escola, por meio de ações cientificamente fundamentadas.

A que distância se situa a atual psicologia da educação em relação a esses enunciados? Não é possível formular uma única resposta a esta questão, na medida em que perspectivas distintas hoje convivem no ensino desta disciplina. Em todo o caso, lançar um olhar curioso para os enunciados antigos pode ajudar a pensar sobre suas possíveis reverberações nos discursos que ainda são os nossos. Melhor ainda, permite refletir sobre a importância dessas velhas questões, mesmo que atualmente nos pare- 
ça apropriado recolocá-las em outros termos. Se já não é o caso de procurar determinar o que é, afinal, a psicologia, valeria pensar sobre o que a psicologia pode vir a ser e que tipo de contribuição pode oferecer à formação dos professores nos dias de hoje. Entre as possibilidades, talvez se pudesse considerar um movimento no sentido contrário ao da conquista da autonomia e da objetividade científica pela psicologia, por meio de sua reaproximação da filosofia, da literatura e da história, as quais, por sua vez, também foram afetadas por suas produções. Tal movimento implicaria a renúncia à suposta segurança proporcionada pelo estudo do aluno como objeto científico. Em compensação, convidaria os professores a admirar cada criança como alguém que não é apenas semelhante às outras da mesma idade, mas uma novidade e uma surpresa. Alguém que não se deve ter pressa em ajustar a uma ordem dada, mas que importa acolher e educar até que encontre ou invente para si próprio um lugar no mundo.

\section{Referências}

Almeida, J. (1947). Noções de psicologia aplicada à educação. São Paulo: Companhia Editora Nacional.

Angelini, A., Pfromm Netto, S., \& Rosamilha, N. (2001). Análise de conteúdo de psicologia educacional. Psicologia escolar e educacional, 5(1), 83-90.

Antunes, M.M. (2007). A psicologia no Brasil: leitura histórica sobre sua constituição. São Paulo: Unimarco/Educ.

Antunes, M.M. (2001a). Bomfim, Manoel José do. Em R. H. F. Campos (Org), Dicionário biográfico da psicologia no Brasil: pioneiros (pp.92-93). Rio de Janeiro: Imago / Brasília, DF: CFP.

Antunes, M.M. (2001b). Sampaio Doria, Antonio de. Em R. H. F. Campos (Org), Dicionário biográfico da psicologia no Brasil: pioneiros (pp.340-341). Rio de Janeiro: Imago / Brasília, DF: CFP.

Antunes, M.M. (2007).A psicologia no Brasil:leitura histórica sobre sua constituição(5a ed.). São Paulo: Unimarco/Educ.

Assunção, M.M.S. (2007). Os livros didáticos de psicologia educacional: pistas para a análise da formação de professores(as): 1920-1960. Temas em Psicologia, 15(1), 69-84.

Assunção, M.M.S. (2008). A psicologia educacional e o ensino da paixão, do prazer e da dor (Minas Gerais, 1920-1960). Cadernos de História da Educação, 7, 247-261.

Azevedo, N. (1936).Psicologia educacional. São Paulo: Companhia Editora Nacional.

Bomfim, M. (1917). Noções de psychologia (2a ed.) Rio de Janeiro: Livraria Francisco Alves.
Carvalho, J.S.F. (2011). A produção do fracasso escolar: a trajetória de um clássico. Psicologia USP, 22(3), 569-578.

Carvalho, M.M.C. (1997). Quando a história da educação é a história da disciplina e da higienização das pessoas. Em M. C. Freitas (Org.), História social da infância no Brasil (pp.269-287). São Paulo: Cortez, USF.

Cysneiros, P.G. (1985). Antipedagogia do livro-texto de psicologia educacional. Revista Brasileira de Estudos Pedagógicos, 66(152), 47-64.

Donzelot, J. (2001). A polícia das famílias(3a ed.). Rio de Janeiro: Graal.

Eddine, E.A.C. (2011). Desenvolvimento e aprendizagem em manuais didáticos de psicologia educacional. Dissertação de Mestrado, Universidade Federal de Mato Grosso do Sul, Campo Grande.

Ferreira, M.G. (1986). Psicologia educacional: análise crítica. São Paulo: Cortez.

Foucault, M. (2004). A arqueologia do saber. Rio de Janeiro: Forense Universitária.

Gioia, P.S. (2001). A abordagem behaviorista radical transmitida pelo livro de psicologia direcionado à formação de professores. Tese de Doutorado, Pontifícia Universidade Católica de São Paulo, São Paulo.

Gouvêa, M.C.S. \& Bahiense, P.N. (2011). A narração da história da psicologia do desenvolvimento e da produção sobre a infância nos livros didáticos. Memorandum, 20, 70-82.

Jácome, M.Q.D. (2006). Apropriações da teoria de Vigotski em livros de psicologia voltados para a formação de professores. Dissertação de Mestrado, Universidade de Brasília, Brasília.

Lourenço, É. \&Tinoco, B.A.F. (2001). Pimentel, lago Victoriano. Em R. H. F. Campos (Org), Dicionário biográfico da psicologia no Brasil: pioneiros(pp.296-297). Rio de Janeiro: Imago / Brasília, DF: CFP.

Lourenço Filho, M.B. (1954). A psicologia no Brasil. Em Azevedo, F. (Org.),As ciências no Brasil(Vol.II, pp.263-296). São Paulo: Melhoramentos.

Magalhães, V. (1900). Lições de pedagogia. Parte 1: Psychologia. Rio de Janeiro: Laemmert Editores.

Mendes, J. (1943). Psicologia educacional: conforme o programa das Escolas Normais de $1^{\circ}$ e $2^{\circ}$ graus. Juiz de Fora: Livraria Editora Lar Católico.

Menezes, D. (1933). Psicologia. Porto Alegre: Livraria do Globo.

Monarcha, C. (1999). Escola Normal da Praça: o lado noturno das luzes. Campinas: Unicamp. 
Nagle, J. (1976). Educação e sociedade na Primeira República.São Paulo: EPU/Edusp.

Olinto, P. (1934). Psicologia. Rio de Janeiro: Editora Guanabara.

Patto, M.H.S. (1990).A produção do fracasso escolar: histórias de submissão e rebeldia. São Paulo: T.A. Queiroz.

Patto, M.H.S. (1999). Ciência e política na Primeira República: origens da psicologia escolar. Em A. M. Jacó-Vilela, F. Jabur, \&H. B. C. Rodrigues (Orgs.), Clio-Psyché: histórias da psicologia no Brasil. Rio de Janeiro: UERJ, NAPE.

Penna, A. (2001). Olinto, P. Em R. H. F. Campos (Org), Dicionário biográfico da psicologia no Brasil: pioneiros (pp.256-258). Rio de Janeiro: Imago/Brasília, DF: CFP.

Penteado Junior, O.A. (1949). Compêndio de psicologia (problemas de psicologia educacional) (2a ed.). São Paulo:ed. do autor.

Pimentel, I. (s.d.). Noções de psicologia aplicadas à educação(6a ed. revista). São Paulo: Melhoramentos.

Rose, N. (2008). Psicologia como uma ciência social. Psicologia \& Sociedade, 20(2), 155-164.

Sampaio Dória, A. (1926). Psychologia. São Paulo: Tipografia do Instituto Ana Rosa.
Schwarcz, L.M. (1993). O espetáculo das raças: cientistas, instituições e questão racial no Brasil. 1870-1930. São Paulo: Companhia das Letras.

Silva, G.B. (2008). A disciplina de psicologia da educação na Escola Normal secundária de Maringá no período de 1950 a 1970. Dissertação de Mestrado, Universidade Estadual de Maringá, Maringá.

Silva, V. B. \& Gallego, R.C. (2011). Construções da ideia de criança 'normal' nas escolas primárias brasileiras: uma análise a partir dos manuais pedagógicos entre finais do século XIX e início do XX Cadernos de História da Educação,10(2).

Tavares, F. (1995). A ordem e a medida: escola e psicologia em São Paulo (1890-1930). Dissertação de Mestrado, Universidade de São Paulo, São Paulo.

Varela, J. (1999). Categorias espaço-temporais e socialização escolar: do individualismo ao narcisismo. Em M. V. Costa (Org), Escola básica na virada do século: cultura, política e currículo (pp. 73-106). São Paulo: Cortez.

Vidal, D.G. (2013). 80 anos do Manifesto dos Pioneiros da Educação Nova: questões para debate. Educação e Pesquisa, 39(3), 577588.

Recebido em:19/09/2014

Reformulado em:07/07/2015

Aprovado em:20/07/2015

\section{Sobre a autora}

Ana Laura Godinho Lima (alglima@usp.br)

Doutora em Educação; docente da Faculdade de Educação da Universidade de São Paulo - São Paulo - SP

Uma primeira versão deste trabalho foi apresentada no X Congresso Luso-Brasileiro de História da Educação (Curitiba, 2014). 
